\title{
RELACIONAMENTOS EM "REDES": UM NOVO TIPO DE AMOR
}

\author{
Carolina Neves Moreira ${ }^{1}$; Alessandra Leila Borges Gomes Fernandes ${ }^{2}$ \\ 1. Bolsista PIBIC/CNPq, Graduando em Licenciatura em Letras com Inglês, Universidade Estadual de Feira de Santana, e- \\ mail: rolneves@hotmail.com.br \\ 2. Orientador, Departamento de Letras e Artes, Universidade Estadual de Feira de Santana, e-mail: allexleilla@ gmail.com
}

PALAVRAS-CHAVE: internet, relacionamento, distância.

\section{INTRODUÇÃO}

A internet, segundo Cartells (2003), surgiu durante a Guerra Fria, quando ocorreram conflitos entre os Estados Unidos e a União Soviética, entre os anos de 1947 a 1991. Inicialmente, era utilizada apenas para uso militar, com o objetivo de estabelecer uma comunicação rápida. Depois, passou a ser utilizada nas pesquisas científicas das instituições acadêmicas, porém os estudantes começaram a usá-la também como forma de comunicação. Segundo Cartells (apud NASCIMENTO, 2007, p.57) foi em 1970 que Ray Tomlinson criou o correio eletrônico, conhecido como e-mail.

Desde então a internet tem evoluído e é moldada às necessidades das pessoas. Temos a criação das redes sociais, sites de relacionamento ou ainda os aplicativos dos celulares, que servem para que haja comunicação entre os indivíduos e aproximação, apesar da distância.

E comum encontrar pessoas que possuem amigos que nunca se encontraram e apenas conversam nas redes sociais ou que já se encontraram e sempre conversam virtualmente por conta da distância. O fato é que sempre há uma mensagem para ser respondida de algum (a) amigo (a)/namorado (a) nas redes sociais. Segundo Nascimento, "a tecnologia se colocaria como aquela que poderia oferecer companhia a quem não tem” $(2007, \mathrm{p} .18)$

Um outro aspecto que é notável e cada vez mais comum são pessoas que criam virtualmente um relacionamento amoroso. A duração de tempo sem que ocorra o encontro pode ser de longo período, que nunca se encontraram, ou que constantemente ocorra um encontro. Segundo Castells (apud NASCIMENTO, 2007, p.12), a comunicação através da internet iniciou-se na década de 1990, enquanto os sites de relacionamento surgiram no final dessa.

O celular, assim como computadores ou outro meio de tecnologia, tornou-se uma necessidade, já que é utilizado tanto para trabalho como para comunicação e diversão. Zygmunt Bauman cita em seu livro Amor Líquido, Sobre a Fragilidade dos Laços Humanos, Jonathan Rowe, que comenta sobre uma cena nos anos de 1990, enquanto a mãe e seus filhos estão na mesa e o pai está ao telefone. O escritor ainda ressalta que nos dias atuais seria comum que todos os componentes da família estivessem conectados em seus aparelhos. Bauman define esse tipo de relacionamento e o chama de 'relações virtuais':

Ao contrário dos relacionamentos antiquados [...], elas parecem feitas sob medida para o líquido cenário da vida moderna, em que se espera e se deseja que as 'possibilidades românticas' (e não apenas românticas) surjam e desapareçam numa velocidade crescente e em volume cada vez maior, aniquilando-se mutuamente e tentando impor aos gritos a promessa de 'ser a mais satisfatória e a mais completa'. Diferentemente dos 'relacionamentos reais', é fácil entrar e sair dos 'relacionamentos virtuais'. (BAUMAN, 2004, p.12-13)

Analisar o relacionamento à distância é importante para entender o sujeito atual nos relacionamentos, já que está sempre conectado em celular, computador ou qualquer outro tipo de tecnologia, além de utilizá-la para encontrar o par perfeito. Serão analisados o livro eu@teamo.com.br(1999), da escritora Leticia Wierzchowski em parceria com Marcelo Pires, 
assim como o filme Do Outro Lado da Linha (2008), dirigido por James Dodson, porque trabalham com o tema utilizando métodos diferentes. Enquanto no livro era utilizado o e-mail, no filme foi utilizado o telefone. A partir deles, será feita uma diferenciação entre esses métodos e analisar esse tipo de amor.

\section{MATERIAL E MÉTODOS OU METODOLOGIA (ou equivalente)}

Durante a pesquisa, o procedimento utilizado foi o da pesquisa bibliográfica, utilizando referências como Zygmunt Bauman, Manuel Castells, Carlize Nascimento e Denis de Rougemont. Além disso, as análises foram feitas através do livro eu@teamo.com.br e do filme Do Outro Lado da Linha. Os matérias utilizados foram papel, caneta, lápis, borracha, acervo da Biblioteca Julieta Carteado e computador.

\section{RESULTADOS E/OU DISCUSSÃO (ou Análise e discussão dos resultados)}

Através das análises do livro eu@teamo.com.bre do filme Do Outro Lado da Linha, foi possível estudar diferentes formas de desenvolvimento de relacionamentos afetivos contemporâneos, tendo-se em conta que as narrativas escolhidas para este recorte utilizavam distintos modos de comunicação para estabelecimento de laços à distância. O livro eu@teamo.com.br foi escrito a quatro mãos por Marcelo Pires e Letícia Wierzchowski, sujeitos que se conhecem por e-mail, estabelecem uma intensa correspondência, se enamoram à distância e, por fim, se conhecem pessoalmente e se casam. O filme Do Outro Lado da Linha traz a narrativa de um casal que se conhece por telefone, se envolve, mas apresenta dificuldades de se conhecer pessoalmente, devido ao medo da quebra de expectativa estabelecida à distância — um aspecto muito comum aos laços afetivos desenvolvidos através de meios de comunicação e redes sociais.

No livro, foi utilizado o e-mail, que, segundo Nascimento, "é um serviço de troca de mensagens mas que não se processa em tempo real [...]" (2007, p. 64), ou seja, o destinatário pode não responder ou ainda responder quando tiver tempo ou quiser. Essa diferença de tempo entre o envio e a resposta é bastante significativa no livro. Algumas vezes ocorre uma resposta em dias ou rapidamente, o que aponta para laços mais maleáveis entre os sujeitos. Durante a exposição da história, a comunicação é realizada rapidamente, porém existem situações em que há um espaço de 4 dias ou mais entre as respostas. Então há um controle de tempo destinado a esse relacionamento - elemento significativo para se compreender porque muitos casais optam por esse tipo de ferramenta enquanto forma de aproximar e, ao mesmo tempo, controlar a relação afetiva.

Além desses aspectos, o e-mail não permite a visualização da pessoa com quem se está se comunicando. O sujeito Marcelo Pires, personagem real da história, conhecia a fisionomia de Letícia por ler uma obra dela e ver a sua foto na orelha do livro, porém, o inverso não acontece, Letícia - que é a escritora gaúcha Letícia Wierzchowski, autora de A casa das sete mulheres - não tinha meios para ver o namorado, exceto se esse lhe enviasse uma foto.

Bauman comentou sobre a tela em branco, no qual o sujeito despeja suas expectativas e desejos sobre outra pessoa. Impressão parecida a que Leticia tem quando diz "Sabe, isso me parece assim como ler um livro sem ver a capa. " (WIERZCHOWSKI, Leticia; PIRES, Marcelo, 1999, p. 27). O e-mail, assim como as redes sociais, é uma forma de comunicação muito mais passível de ser moldada, pois é possível apagar e reescrever as mensagens (e com elas as reações pessoais) antes de enviá-las. Ocorre então uma quebra da espontaneidade, que é inevitável em uma conversa frente a frente.

No filme, o método utilizado entre os personagens para que ocorra a comunicação é o telefone. Um dos aspectos que o diferencia do e-mail é o conhecimento e familiarização da voz do interlocutor. Esse elemento sensorial é capaz de dar identidades aos pares. Se torna mais fácil imaginar o sujeito do outro lado através da tonalidade, simpatia, gravidade, timbre, entre 
outros aspectos da voz. Em certa altura do filme, o personagem Grander, em uma conversa com seu amigo diz: "[...] a voz dessa menina é legal, a voz dela é doce, ela ri das minhas piadas, tem um ótimo senso de humor, inteligente, passa uma boa vibração [...]". Há, aí, uma criação de identidade e uma expectativa para que essas sejam correspondentes no plano real, sito é, quando se encontrarem. No decorrer do filme, veremos que justamente por criar uma identidade entre a voz ouvida no telefone e o tipo de mulher que atrai a Grander, ao marcarem um encontro, ele não consegue identificar Priya. Já havia uma imagem projetada de uma mulher loira, que tinha aquele timbre de voz e se encaixava nas expectativas de Grander. A personagem feminina, por outro lado, já havia pesquisado sobre o rapaz na internet, viu sua foto e não foi às cegas ao encontro, do mesmo modo como aconteceu no livro eu@teamo.com.br, em que um dos personagens conhecia a foto do outro. Percebemos, então, que há elementos complexos e sutis na formação de laços afetivos à distância, com variações que vão desde o meio usado para o par se comunicar, passando por demandas particulares de cada um, até a dificuldade de acertar expectativas e projeções na vida real, quando o casal revolve se conhecer.

Para a maioria dos autores teóricos (Bauman, Nascimento, Castells), a distância e a tecnologia usada para desenvolvimento de laços afetivos servem muitas vezes como uma proteção da desilusão ou decepção amorosa, e isso é bem exemplificado pelo filme quando a personagem feminina, Prya, cria uma imagem bastante fantasiosa de Grander, a partir das conversas desenvolvidas com ele, definidas por ela como 'mágicas'.

\section{CONSIDERAÇÕES FINAIS (ou Conclusão)}

O relacionamento à distância promovido por novas tecnologias é ainda um espaço novo para se compreender comportamentos e mudanças nas formas de relacionamentos contemporâneos. Apesar de Bauman não ser muito positivo a esses mecanismos contemporâneos de encontros amorosos - já que, para ele, é possível deletar muito facilme nte o outro, o que faz com que as pessoas se protejam do encontro real com as outras -, acreditamos que é necessário pesquisar mais sobre o assunto, num recorte talvez mais amplo, que também envolva as histórias reais, de pessoas comuns, que se conhecerem através da internet ou outro meio de comunicação, mantiveram um laço à distância e conseguiram estabelecer, depois, uma relação amorosa. Defendemos que os elementos positivos envolvidos nesse tipo de relação são: a facilidade em administrar o tempo destinado àquele relacionamento - pois o sujeito pode responder e-mails e postagens quando puder, ou, ainda, ligar quando desejar - e o controle maior das reações e ímpetos.

É visível que ocorre a criação de expectativas em ambos os corpus analisados. No livro vemos esse fator quando Letícia pergunta como é a fisionomia do personagem, enquanto no filme ocorre a decepção de Prya por Grander ir a seu encontro, mas não identificá-la, por esperar uma moça loira. Ambos desenvolveram ideias de como o outro seria.

Ainda assim, temos uma narrativa que expõe um relacionamento iniciado à distância que, quando transportado para a vida real, deu certo (pois Marcelo e Letícia se casam), e outro que não resistiu à quebra de expectativas. Trata-se de uma história verídica (a do livro) e outra de ficção (a do filme), que põem em circulação os aspectos acima discutidos numa relação à distância mediada pelas novas formas de comunicação.

\section{REFERÊNCIAS}

BAUMAN, Zygmunt. Amor líquido: sobre a fragilidade dos laços humanos. Rio de Janeiro: Jorge Zahar Editor, 2004.

CASTELLS, Manuel. A galáxia da Internet: reflexões sobre a Internet, os negócios e a sociedade. Rio de Janeiro: Zahar, 2003.

DODSON, James. Do Outro Lado da Linha, EUA, 2008. 1h46min.

JONZE, Spike. Ela, EUA, 2013. 2h6min. 
LEILLA, Állex. Préterito imperfeito, uma coreografia verbal do amor na contemporaneidade. Feira de Santana, 2016.

NASCIMENTO, Carlize Regina Ogg. Do amor em tempos de internet: análise sociológica das relações amorosas mediadas pela tecnologia. Universidade Federal do Paraná, Setor de Ciências Humanas, Letras e Artes, Programa de Pós-graduação em Sociologia. Defesa: Curitiba, 2007. Disponível: < http//acervodigital.ufpr.br/handle/1884/12128 > Acesso em: 30 jun. 2017.

ROUGEMONT, Denis de. O amor e o Ocidente. Rio de Janeiro: Editora Guanabara, 1988.

SALWEN, Hal. Denise está Chamando, EUA, 1995. 1h20min.

SANT'ANNA, Denise. As infinitas descobertas do corpo. Cadernos Pagu, São Paulo, n. 14, 2000 ,

p. 235-249.

Disponível em:

<www.bibliotecadigital.unicamp.br/document/?down=51333> Acesso em: 20 jul. 2017

SPONVILLE, André, Comte. O pequeno tratado das grandes virtudes. São Paulo: Martins Fontes, 1999.

WIERZCHOWSKI, Letícia; PIRES, Marcelo. eu@teamo.com.br: o amor nos tempos da internet. L\&PM, 1999. 